\title{
A Review of Dietary Probiotics in Poultry
}

\author{
Seyed Mohammad Ali Aziz Mousavi', Hamideh Mahmoodzadeh Hosseini', Seyed Ali Mirhosseini1* \\ ${ }^{1}$ Applied Microbiology Research Center, Systems Biology and Poisonings Institute, Baqiyatallah University of Medical Sciences, \\ Tehran, Iran
}

Corresponding Author: Seyed Ali Mirhosseini, Assistant Professor, Applied Microbiology Research Center, Systems Bbiology and Poisonings Institute, Baqiyatallah University of Medical Sciences, Vanak Sq. Molasadra St., Tehran, Iran. Tel: +98-21-82482568, Fax: +98-21-88068924, Email: ali.mirh@gmail.com

Received March 1, 2018; Revised March 29, 2018; Accepted April 10, 2018; Online Published June 20, 2018

\begin{abstract}
The use of probiotics has rapidly grown in recent years, enhancing the performance of broilers and leading to the production of products free of any probiotic trace. Recent evidence suggests that the use of microbial probiotics can play a significant role in the future of the poultry industry. Although this method is not complete yet, it can be employed by human societies as a useful tool to maximize poultry products, enhance the health, and ensure the safety of food sources. Some reports show that the application of probiotics in the feed of broilers can lead to positive outcomes such as increased weight and improved feed conversion ratio (FCR).

Keyword: Probiotic, Broiler, Hen, Turkey, Growth, Health

Citation: Aziz Mousavi SMA, Mahmoodzadeh Hosseini H, Mirhosseini SA. A review of dietary probiotics in poultry. J Appl Biotechnol Rep. 2018;5(2):48-54. doi:10.29252/jabr.05.02.02.
\end{abstract}

\section{Introduction}

Probiotics are nonpathogenic living organisms present in some foods which have positive effects on the health of the hosts if they enter the body in sufficient amounts. Imani et $\mathrm{al}^{1}$ concluded that probiotic therapy as an inexpensive and non-invasive strategy can reduce pathophysiologic symptoms and improve various liver diseases with no complications. Khani et $\mathrm{al}^{2,3}$ reported various potential positive effects, including the improve health of the digestive system, increase body immunity, reduced symptoms of lactose intolerance, decreased allergy, reduced risk of particular cancers, treatment of colitis, reduced serum cholesterol concentration, reduced blood pressure in those with hypertension, alleviated respiratory and Helicobacter pylori infections. In nature, the infants of animals receive protective flora from mothers or the environment. Nevertheless, contemporary childbirth and postpartum care methods limit contact with mothers and provide synthetic foods and environments. As a result, some natural parts of the microflora of infants' digestive system, which cause resistance to diseases do not exist anymore. Diet, antibiotics, and stress also affect the flora in adults. The application of probiotic supplements can compensate for this deficiency. Therefore, the use of these compounds does not create something, which does not naturally exist. Rather, it fully regenerates the protective ability of flora. ${ }^{4}$ Numerous studies have been conducted on probiotics with different results. The present study and similar studies attempt to provide a scientific basis for the concept of probiotics and delineate the way modern probiotics are manufactured. This hopefully paves the way for required studies and provides a basis for a more rational approach to the selection of probiotic strains in the future.

\section{Prebiotics, Probiotics, and Symbiotic}

Prebiotics are food nutrients which are indigestible or minimally digestible in the digestive system and their positive effect on human health is through the stimulation of growth or increase in the activity of a limited number of probiotic bacteria in the large intestine. This role is played by minimally digested and fermentable carbohydrates in the small intestine, leading to the growth of Bifidobacteria and some gram-positive bacteria. In fact, carbohydrates pass the small intestine, move to lower parts, and become accessible to the bacteria in the large intestine. Lactulose, galactooligosaccharides, fructooligosaccharides, inulin, and their hydrolyzed metabolites, maltooligosaccharide, are among prebiotics which are usually used in human nutrition. Probiotics improve the performance and health status of birds through competitive exclusion and creating a balance in the microbial population in the digestive system. ${ }^{5}$ Based on Fuller's ${ }^{6}$ definitions, probiotics are microbial nutritional supplements which exert positive effects on the host by improving the microbial balance in the intestine. This definition emphasizes the living nature of probiotics. Synbiotics are a combination of beneficial probiotic species and prebiotic carbohydrates, and the simultaneous consumption of these compounds has

Copyright (C) 2018 The Author(s). This is an open-access article distributed under the terms of the Creative Commons Attribution License (http:// creativecommons.org/licenses/by/4.0), which permits unrestricted use, distribution, and reproduction in any medium, provided the original work is properly cited. 
useful synergistic effects. In fact, the superiority of and major reason for the use of synbiotics are that, without a prebiotic, a probiotic would have little survival in the environment because prebiotics are the food source of probiotics. ${ }^{7}$ Due to the beneficial and synergistic effects of using a mixture of probiotics and prebiotics in good, it is recommended to refer to them as synbiotics.

Pournazari et $\mathrm{al}^{8}$ concluded that a stressful environment causes various diseases in broilers. Probiotics, prebiotics, and essential oils of Thymus vulgaris L. can be used in poultry farming as an alternative to antibiotics. Feeds contained 1-2 g/ $\mathrm{kg}$ Fermacto, $1-2 \mathrm{~g} / \mathrm{kg}$ of Bioplus, and $0.5-1 \mathrm{~g} / \mathrm{kg}$ of T. vulgaris $\mathrm{L}$. essential oil while the feed of the control group did not contain any additives. Compared to the control group, Fermacto, Bioplus, and T. vulgaris L. essential oil led to weight gain and feed intake. The feed was increased with $2 \mathrm{~g} / \mathrm{kg}$ of Fermacto. Moreover, $1 \mathrm{~g} / \mathrm{kg}$ of T. vulgaris $\mathrm{L}$. essential oil improve feed conversion ratio (FCR) but reduced the relative weight of thighs and wings. A significant difference was observed between groups in terms of blood parameters. Therefore, Fermacto, Bioplus, and T. vulgaris L. essential oil microorganisms improve mean daily weight gain of broilers with little effect on the carcass, organs, and plasma components. Technomouse prebiotic supplement significantly affected weight gain, feed intake, FCR, blood constitutes, and immunoglobulins in turkeys. Still, feed protein level significantly affected weight gain and FCR in the final stage, uric acid concentration on day 98, and IgM titer on day 49. Therefore, this study provides evidence supporting the fact that prebiotic supplements in turkey feed with different protein levels do not affect growth performance, blood biochemistry, or hemagglutination inhibition. The protein level of feed had more effects on the examined parameters compared to prebiotics. ${ }^{9}$ Karimi et al ${ }^{10}$ investigated the effects of some probiotics, including Bioplus, PrimaLac, Tipax, and Protexin on ostriches and found that, in treatments using BioPlus and PrimaLac, total cholesterol level (157 and $210 \mathrm{mg} / \mathrm{dL}$ ) was increased compared to the control group (119 mg/dL), but total cholesterol was slightly decreased for the group receiving Tipax $(79 \mathrm{mg} / \mathrm{dL})$ in its feed $(P>0.05)$. Consequently, commercial probiotics had different effects on growth performance, carcass characteristics, and hematological parameters.

\section{Probiotics Microbes and Their Characteristics}

These microorganisms are nonpathogenic and are not related to bacteria causing diarrhea. They can't transfer antibioticresistance genes and maintain genetic stability. Probiotic microbes can resist to gastric acid, bile, and digestive enzymes, and can attach to the intestinal wall and fight off pathogens. They have anti-mutagenic effects and play a role in reducing serum cholesterol. Probiotic microbes also stimulate the immune system without causing inflammation and have anti-cancer effects. Furthermore, they can increase bowel movement, maintain the health of mucus, and improve the bioavailability of food components. ${ }^{11}$

\section{Probiotics' Mechanism of Action}

Increasing colonization resistance or direct pathogen inhibitive effects are important factors which enable probiotics to reduce the incidence rate and duration of diseases. Various types of probiotics are demonstrated for inhibiting pathogenic bacteria in vitro and in vivo through various mechanisms. Probiotics in poultry act as follows: (1) maintaining normal intestinal microflora by competitive opposition and exclusion. ${ }^{12,13}$ (2) changing metabolism by increasing the activity of digestive enzymes and reducing the activity of bacterial enzyme and ammonia production ${ }^{14}$; (3) improving digestion and the amount of nutrition ${ }^{15}$ and (4) activating the immune system. ${ }^{16-18}$ Probiotics can be used to control zoonoses and common diseases in poultry. In traditional conditions, competitive exclusion in poultry shows the consumption of intestinal microbes naturally found in poultry and chicks which are ready to be placed in the nest of a brood of chicks. ${ }^{19,20}$ First discussed this when they attempted to control Salmonella infantis in Finnish broilers. They discovered that small amounts of Salmonella challenge (1-10 cell per culture) were sufficient for the onset of salmonellosis in chicks. Moreover, they determined that chicks are most predisposed to Salmonella contamination in the first week of hatching. The consumption of Lactobacillus species did not create protection. Therefore, they had to evaluate the uncontrolled number of intestinal bacteria in adult chicks which were resistant to Salmonella infantis. This method was later called Nurmi method or competitive exclusion. The competitive exclusion method of inoculating one-day-old chicks with grown microflora clearly shows the effect of intestinal microbes on intestinal function and disease resistance. ${ }^{21,22}$ Although competitive exclusion is compatible with the definition of probiotics, this method provides grown intestinal microbes instead of adding one or multiple bacterial species to microbes created for each chick. The inoculation of one-day-old chicks grown with competitive exclusion or more classic probiotics acts as a good model for determining the activity and effectiveness of these microorganisms. This is also commercially important due to the predisposition of oneday-old chicks to infection. Using this model, some probiotics are demonstrated for reducing colonization and transmission of Salmonella and Campylobacter. ${ }^{23,24}$

Based on consumption rate, probiotics reach a large amount of acid lactic bacterium to the intestinal route. These microorganisms are known for adjusting the intestinal environment and reaching enzymes and other useful matters to the intestines. ${ }^{25}$ Feeding chicks with Lactobacillus acidophilus supplement or the mixture of Lactobacillus cultures significantly $(P<0.05)$ increases amylase levels after 40 days of feeding. Entering probiotics (a mixture of multi-species of Lactobacillus and Streptococcus faecium) increases the activity of carbohydrate in the small intestine of piglets. Lactobacillus colonizes in the intestine and may secrete enzymes, thereby increasing the activity of intestinal amylase. ${ }^{26,27}$ It is established that probiotics alter intestinal $\mathrm{pH}$ and microflora in order to facilitate the activity of intestinal enzymes and digestion. ${ }^{28}$ Moreover, probiotics may reduce the production of ammonia in intestines and thus improve the health status of birds. ${ }^{29}$

Probiotic is a general term, and products can include yeast 
cells, bacterial cultures, or both, and microorganisms are stimulated to adjust the intestinal environment to facilitate health status and improve nutritional function. ${ }^{28}$ Mechanisms through which probiotics improve the function of FCR are altering the intestinal flora, increasing the growth of anaerobic microorganisms and gram-positive bacteria which produce lactic acid and hydrogen peroxide, preventing the growth of intestinal pathogens, and increasing the digestion and consumption of nutrients. Therefore, major outcomes of using probiotics include an increase in growth, ${ }^{30}$ reduction in losses, ${ }^{31}$ and improvement of FCR. ${ }^{30}$

\section{The Role of Probiotics in Changing the Composition and} Metabolism of Microbial Flora

Intestinal microbial flora is often constant in each person, although it differs across individuals. ${ }^{32,33}$ Still, the prescription of probiotics in infants and adults leads to a change in the microbial profile and metabolic activities of the stool. Although these variations are small, they are usually sufficient for correcting the course of the disease in case of prescription in pathogenic conditions. In most cases, the prescription of probiotics increases the number of Bifidobacteria and Lactobacillus, reduces the $\mathrm{pH}$ of stool, and decreases the activity of bacterial enzymes. ${ }^{34}$

\section{Criteria for Selecting Probiotics in the Poultry Industry}

Probiotic bacteria must follow the following conditions: They must be natural flora of the intestine; they must be able to attach to intestinal epithelium in order to overcome potential barriers such as low gastric $\mathrm{pH}$, presence of bile acid in the intestine, and competition with other microorganisms in the intestinal route. ${ }^{35,36}$ The competition of most species selected by laboratory and in vivo assays has been evaluated to control their continuation in chicks. ${ }^{37}$ Moreover, probiotics must exert their potential positive effects (e.g. improving nutrition and increasing the immune response) in the host. As a result, they must be made appropriate for industrial processes technologically and under normal storage conditions.

\section{The Effect of Probiotics Against Salmonella Contamination} The use of probiotic spray for newly hatched chicks through administration in the first drinking water is a very efficient method for controlling the colonization of Salmonella in poultry intestine. Blankenship et $\mathrm{al}^{38}$ reported that the prevalence of Salmonella in ceca and processed carcass was significantly decreased from $41 \%$ in control flocks to $10 \%$ in treated flock. This shows that chicks treated with probiotics can serve as a useful means for reducing salmonella contamination. The same authors used mucosal competitive exclusion (MCE) to treat newly hatched chicks through water spray and reported that initial feed, water, and litter contamination were at a low frequency $(>10 \%)$ while eggshell fragments and chick paper pads were frequently contaminated $(<50 \%)$. After three weeks of growth, litter contamination, skin with feathers, and ceca significantly differed $(P<0.05)$, while no reduction was observed in the treated flock compared to the control flock.
Competitive Exclusion

Tortuero $^{39}$ used live bacteria and observed that the use of Lactobacillus leads to functions similar to those obtained following the use of antibiotics. Competitive exclusion indicates the prevention of a bacterium's entry to the attachment sites by filling the accessible space. In this way, the pathogenic bacterium is viewed as a competitor and removed by competition over attachment site.

\section{Digestion and Enzyme Activity}

In vitro studies have shown that digestive enzymes of Lactobacillus species are enriched in the intestine. Szylit et a ${ }^{40}$ reported that 2 out of 5 Lactobacillus strains separated from a male chick showed amylase activity. Jin et $\mathrm{al}^{41}$ reported that amylase activity in the small intestine is increased due to the Lactobacillus population fed to broilers, but has no effect on lipolytic and proteolytic activities. Collington et $\mathrm{al}^{42}$ showed that including a probiotic (mixture of various species of Lactobacillus plantarum, L. acidophilus, Lactobacillus casei, and Streptococcus faecium) in pig's diet led to considerable carbohydrataseactivities in the mucosal membrane.

\section{Bacterial Enzyme Activity}

Goldin and Gorbach ${ }^{43}$ reported that nitroreductase, azoreductase, beta-glucuronidase activities in the intestine can lead to a decrease by feeding with $L$. acidophilus supplements. Similar results have been observed in humans. ${ }^{44}$ A similar reduction in beta-glucuronidase has been seen in chicks fed with $40 \%$ yogurt in drinking water ${ }^{45}$ and in pigs. ${ }^{46}$

\section{Ammonia Production}

It is reported that probiotics containing L. acidophilus, S. faecium, and Bacillus subtilis decrease ammonia concentration in the excreta and little of broilers. ${ }^{29}$

Increasing Feed Intake and Digestion

Pet's intestinal bacterial flora plays a significant role in feed absorption and digestion. They participate in the metabolism of nutrients such as carbohydrates, proteins, lipids, and minerals, as well as in the synthesis of vitamins. Nahanshon et $\mathrm{al}^{47-50}$ detected that adding Lactobacillus in corn/soy or corn/barley/soy diet stimulates appetite and increases fat, nitrogen, calcium, phosphorous, copper, manganese, and their retainment in layers.

\section{Enterotoxin Inactivation}

The substance produced by a probiotic may be inactivated by enterotoxins produced by pathogenic bacteria. Various studies with Lactobacillus bulgaricus indicated that these small microscopic organisms produce a metabolite which inactivates the enterotoxin release by various forms of $E$. coli. ${ }^{51,52}$

\section{Stimulation of Body Immune System}

Immune resulting from the exposure of intestine to various forms of antigen, such as pathogenic bacteria and protein in feed, is important in young animals' defense against intestinal 
infections. ${ }^{53,54}$ Dunhan et $\mathrm{l}^{55}$ reported that birds treated with Lactobacillus reuteri further showed ideal and deeper cryptal villi which improve $\mathrm{T}$ cell function responses and increase the secretion of the IgM anti-Salmonella antibody.

\section{Studies on Probiotics and Symbiotic in Poultry}

Effects of Probiotics on Performance and Growth

Hosseini et $\mathrm{al}^{56}$ examined the effect of adding probiotics containing Streptococcus and Bifidobacterium on the performance of broilers. In terms of feed intake, carcass percentage, and abdominal fat weight, no significant difference was observed between treatments. Mean live weight and FCR in the 0 -21-day period was significantly $(P<0.05)$ improved in groups receiving probiotics compared to the control group, but this effect was not significant throughout the entire experiment.

Mahajan et $\mathrm{al}^{57}$ reported a significant $(P<0.05)$ increase in the weight of edible viscera, warm carcass weight, cold carcass weight, and carcass percentage of broilers fed with probiotics (Lactobacillus + Saccharomyces). Jin et $\mathrm{al}^{58}$ observed a significant increase in the weight of chicks fed with various levels of probiotics compared to the control group. The positive effect of probiotics on chick weight was also reported by other researchers, e.g. Midilli and Tuncer and Kabir et al. ${ }^{59}$, ${ }^{60}$ However, others did not observe such an increase in chick weight. ${ }^{61-63}$

The effect of using organic acids and probiotics was examined on the performance and carcass characteristics of broilers. The examined properties were feed intake, body weight gain, FCR, and carcass characteristics. In terms of weight gain in the growth period, breast percentage, and abdominal fat percentage, no significant difference was observed between treatments $(P>0.05)$. For feed intake, weight gain, FCR, and abdominal fat percentage, the treatment containing probiotic and that containing a mixture of probiotic and organic acids yielded the best results. Results of this experiment showed that the use of organic acids and probiotics lead to better performance in the examined properties in male Ross 308 broilers compared to the feed containing antibiotics. ${ }^{64}$

Effects of Probiotics on Immune Responses

Rowghani et $\mathrm{al}^{65}$ examined the use of probiotics and other additives in the feed of broilers and their effects on broilers' immune system. In this study, the resistance of the immune system was examined with the use of probiotic, ToxiBan (commercial compound \#1), Formicin (commercial compound \#2), and a mixture of probiotic and ToxiBan in the feed of broilers. FCR was significantly better $(P>0.01)$ in ToxiBan treatment compared to other treatments. In general, in this study, a significant difference was found between various treatments in terms of body weight, feed intake, FCR, and blood antibody titer $(P<0.01)$.

Kabir et al ${ }^{60}$ investigated the effects of probiotics on immune response in the body of chicks and reported a significant increase $(P<0.01)$ in antibody production. They also considered the difference in the weight of spleen and bursa to be related to the difference in antibody production level in the group fed with probiotics and the control group. Dalloul et al ${ }^{66}$ explored the effects of feeding with Lactobacillus probiotic on the intestinal immune response of broilers during the course of Eimeria acervulina infection and showed that the probiotic continues providing some immune indices by adjusting immunity despite the relatively high amount of $E$. acervulina. Haghighi et $\mathrm{al}^{67}$ showed that probiotics increase natural intestinal serum and antibodies for some external antigens in broilers. Khaksefidi and Ghoorchi ${ }^{68}$ reported that antibody titer in $50 \mathrm{mg} / \mathrm{kg}$ probiotic-supplemented group is significantly higher 5 and 10 days after immunization compared to the control group when sheep-red-blood cells (SRBC) is injected in 7 and 14 days of age.

The Effect of Probiotics on Intestinal Microbiology and Morphology

Gharib et $\mathrm{al}^{69}$ compared the effect of probiotic and prebiotic on experimental contamination with Campylobacter jejuni in broilers. Experimental treatments included positive control (contaminated), negative control (non-contaminated), probiotic (PrimaLac), and prebiotic (Fermacto). The highest and lowest FCR at 49 days of age were observed in positive control and negative control groups, respectively $(P<0.05)$. Moreover, the treatment of negative control had the highest weight gain and feed intake at 49 days of age from among treatments $(P<0.05)$. Kabir et $\mathrm{al}^{60}$ indicated that probiotics can remove harmful pathogens through competition for attachment to the wall of the small intestine. Furthermore, broilers fed with probiotics underwent intestinal histological changes, including a variation in the length of villi and increase cell surface. Broilers fed with Lactobacillus strains have a smaller number of coliforms in their stool.

\section{Effects of Probiotics on Meat Quality}

$\mathrm{Kabir}^{70}$ and Kabir et $\mathrm{al}^{12}$ examined the effect of probiotics on the microbiology and gustatory factors of broiler meat and showed that the consumption of probiotics enhances the quality of meat before and after freezing. Mahajan et $\mathrm{a}^{57}$ reported a significant increase in the score of meat quality factors, including appearance, texture, succulence, and wholesomeness in broilers fed with probiotic (lactosaccharose). However, flavor and taste showed lower scores. Loddi et $\mathrm{al}^{71}$ reported that neither probiotics nor antibiotics affect sensory properties (color and smell intensity, unnatural taste, tenderness, succulence, wholesomeness, color property, and general properties) of the thigh and breast meat. Zhang et $\mathrm{al}^{72}$ conducted an experiment of 240 one-day-old male broiler chicks to examine the effects of Saccharomyces cerevisiae cell components on meat quality. They reported that meat tenderness can be increased by whole yeast or the selected $S$. cerevisiae.

\section{Factors Affecting the Probiotic Effect}

The interactions between a microbial additive and the host and its digestive system microflora lead to various effects with a very complex nature. Some factors affecting this final effect are examined below. 


\section{Quality Assurance}

The survival property of a probiotic product is of vital importance. However, the number of living microorganisms is not always the same as the number reported on labels. Another complicating factor is the difference in strains which can occur in one species. It is quite likely that the consumption of 2 probiotics produced from similar and equal bacterial species should lead to different results. Therefore, when comparing 2 probiotic products containing similar species, it is essential to know whether the employed cultures for the production of one probiotic product originate from one strain. ${ }^{4}$

\section{Consumption Amount and Method}

Experiments on rats and humans reveal that the effect of probiotics is ceased when consumption is stopped. Similarly, in pigs and poultry, probiotics cannot be found in the digestive system seven days after consumption. ${ }^{4}$

\section{Age and Type of Animal}

Animals' digestive system microflora, physiology, and immune status change and their status is not the same during infancy, after weaning, and in puberty. As the flora in the infancy period is still changing, as a general principle, affecting the flora is easier over this period compared to other stages of life, since flora becomes relatively stable later. Therefore, it can be recommended that the consumption of probiotics should start as quickly as possible after birth. Alterations in diet composition may also occur in this period. Today, we are aware that variations occur in human infants' digestive system flora after weaning and the consumption of formula or solid food. It has been shown that milk contains an agent which promotes the growth of Bifidobacteria and can affect the response emerging after the consumption of probiotics containing these organisms. The debilitative effect of additives containing lactobacillus acidophilus on enzymatic activity depends on the type of diet. No such effect has been observed in rats receiving a diet containing seeds, whereas a positive response has been achieved in rats receiving a diet containing meat. ${ }^{4}$

Flora Composition in the Animal Host's Digestive System It is possible that probiotics somehow act by affecting the microflora composition in the host's intestine. In his way, the prerequisite for obtaining a positive response after the consumption of a probiotic compound wound be the microbial presence with an undesirable effect such as reduced growth. Therefore, it is possible that no effect would be exerted by probiotics if a growth-debilitating organism is not present. Similarly, if the probiotic organism is naturally acquired, no response would be obtained following its consumption. The need for consuming probiotic additive is due to today's unnatural life imposed on humans and animals. A clear example is a poultry whose eggs are removed from the brooding hen and kept in a clean incubator. ${ }^{4}$

Type of Product

The importance of establishment may be decreased upon the continued consumption of probiotics, because it provides the opportunity for the presence of a large number of probiotic microorganisms in the digestive system without needing establishment or growth. Some probiotic organisms such as Aspergillus oryzae - which are unlikely to grow in rumen or affect rumen's metabolic activity - must act in this way. Nevertheless, even if probiotics are designed such that they would not have to be consumed continually, the maximization of survival in digestive system and performance of the abovementioned experiments may prove useful in the selection of the most effective strains. ${ }^{4}$

\section{Production Methods}

The behavior of an organism in the digestive system can be affected by its method of growth and harvest from the environment; for instance, attachment to mucous is affected by the energy source of carbohydrate used for growth or the presence of milk at the site of attachment. The growth of E. faecium in milk enhances the immunization against diarrhea caused by E. coli in pigs. The suspension of probiotic organisms in milk may also improve their ability to attach and, therefore, a better establishment in the digestive system. The phase of the growth cycle in which the probiotic organisms are obtained may also affect their attachment to the mucosal cell. ${ }^{4}$

\section{Conclusions}

Today, the increases in population and necessity of access to healthy sources of protein have caused the ever-increasing popularity of the poultry industry. The dense growth of poultry increases the risk of various microbial infections such as Salmonella, Campylobacter, and Clostridium perfringens. Antibiotics are widely used to improve growth factor and prevent and treat various infections. The presence of antibiotic residuals in meat and egg, followed by antibiotic resistance, threaten the health of consumers. Considering this increasing trend of antibiotic consumption and the ever-increasing prevalence of antibiotic resistance, alternative compounds such as probiotics and prebiotics are being employed today. Their consumption as nutritional supplements in poultry diet is expanding due to their health-promoting effects, such as increasing growth, improving eggs, fortifying the immune system, and enhancing the health status.

\section{Authors' Contributions}

All authors equally contributed to the current study.

\section{Conflict of Interest Disclosures}

The authors declare they have no conflicts of interest.

\section{References}

1. Imani Fooladi AA, Mahmoodzadeh Hosseini H, Nourani MR, Khani S, Alavian SM. Probiotic as a novel treatment strategy against liver disease. Hepat Mon. 2013;13(2):e7521. doi:10.5812/ hepatmon.7521.

2. Khani S, Mahmoodzadeh Hosseini H, Taheri M, Nourani MR, Imani Fooladi AA. Probiotics as an alternative strategy for prevention and treatment of human diseases: a review. Inflamm Allergy Drug Targets. 2012;11(2):79-89.

3. Khani S, Motamedifar M, Golmoghaddam H, Mahmoodzadeh 
Hosseini H, Hashemizadeh Z. In vitro study of the effect of a probiotic bacterium Lactobacillus rhamnosus against herpes simplex virus type 1. Braz J Infect Dis. 2012;16(2):129-135.

4. Afshar Mazandaran N, Rajab A. Probiotics and their use in animal and poultry diets. Tehran: Noorbakhsh; 2001. [Persian].

5. Stavric S, Kornegay ET. Microbial probiotics for pigs and poultry. In: Wallace RJ, Chesson A, eds. Biotechnology in Animal Feeds and Animal Feeding. Wiley; 2008:205. doi:10.1002/9783527615353. ch10.

6. Fuller R. History and development of probiotics. In: Fuller R, ed. Probiotics: The scientific basis. Dordrecht: Springer Netherlands; 1992:1-8.

7. Markowiak P, śliżewska K. Effects of probiotics, prebiotics, and synbiotics on human health. Nutrients. 2017;9(9):1021. doi:10.3390/nu9091021.

8. Pournazari M, AA-Qotbi A, Seidavi A, Corazzin M. Prebiotics, probiotics and thyme (Thymus vulgaris) for broilers: performance, carcass traits and blood. Rev Colom Cienc Pecua. 2017;30(1):310. doi:10.17533/udea.rccp.v30n1a01.

9. Vahabi-Asil O, Bouyeh M, Qotbi A, et al. Effects of a prebiotic on growth performance, blood parameters and immunity response of turkeys fed low protein diets. Eur Poult Sci. 2017;81. doi:10.1399/ eps.2017.196.

10. Karimi-Kivi R, Dadashbeiki M, Seidavi A. Growth, body characteristics and blood parameters of ostrich chickens receiving commercial probiotics. Span J Agric Res. 2015;13(1):1-11. doi:10.5424/sjar/2015131-6146.

11. Kaur IP, Chopra K, Saini A. Probiotics: potential pharmaceutical applications. Eur J Pharm Sci. 2002;15(1):1-9.

12. Kabir SML, Rahman MM, Rahman MB. Potentiation of probiotics in promoting microbiological meat quality of broilers. J Bangladesh Soc Agric Sci Technol. 2005;2(3-4):93-96.

13. Kizerwetter-Swida $M$, Binek $M$. Protective effect of potentially probiotic Lactobacillus strain on infection with pathogenic bacteria in chickens. Pol J Vet Sci. 2009;12(1):15-20.

14. Yoon C, Na CS, Park JH, Han SK, Nam YM, Kwon JT. Effect of feeding multiple probiotics on performance and fecal noxious gas emission in broiler chicks. Korean J Poult Sci. 2004;31(4):229-235.

15. Awad WA, Bohm J, Razzazi-Fazeli E, Ghareeb K, Zentek J. Effect of addition of a probiotic microorganism to broiler diets contaminated with deoxynivalenol on performance and histological alterations of intestinal villi of broiler chickens. Poult Sci. 2006;85(6):974979. doi:10.1093/ps/85.6.974

16. Apata D. Growth performance, nutrient digestibility and immune response of broiler chicks fed diets supplemented with a culture of Lactobacillus bulgaricus. J Sci Food Agric. 2008;88(7):1253-1258. doi:10.1002/jsfa.3214.

17. Nayebpor M, Farhomand P, Hashemi A. Effects of different levels of direct fed microbial (Primalac) on growth performance and humoral immune response in broiler chickens. J Anim Vet Adv. 2007;6(11):1308-1313.

18. Brisbin JT, Zhou H, Gong J, et al. Gene expression profiling of chicken lymphoid cells after treatment with Lactobacillus acidophilus cellular components. Dev Comp Immunol. 2008;32(5):563-574. doi:10.1016/j.dci.2007.09.003.

19. Rantala M, Nurmi E. Prevention of the growth of Salmonella infantis in chicks by the flora of the alimentary tract of chickens. Br Poult Sci. 1973;14(6):627-630. doi:10.1080/00071667308416073.

20. Nurmi E, Rantala M. New aspects of Salmonella infection in broiler production. Nature. 1973;241(5386):210-211. doi:10.1038/241210a0.

21. Stern NJ, Cox NA, Bailey JS, Berrang ME, Musgrove MT. Comparison of mucosal competitive exclusion and competitive exclusion treatment to reduce Salmonella and Campylobacter spp. colonization in broiler chickens. Poult Sci. 2001;80(2):156-160. doi:10.1093/ps/80.2.156.

22. Nisbet DJ, Tellez GI, Lowry VK, et al. Effect of a commercial competitive exclusion culture (Preempt) on mortality and horizontal transmission of Salmonella gallinarum in broiler chickens. Avian Dis. 1998;42(4):651-656.

23. Fritts $\mathrm{CA}$, Kersey $\mathrm{JH}$, Motl MA, et al. Bacillus subtilis C-3102 (Calsporin) improves live performance and microbiological status of broiler chickens. J Appl Poult Res. 2000;9(2):149-155. doi:10.1093/japr/9.2.149.

24. Line JE, Bailey JS, Cox NA, Stern NJ, Tompkins T. Effect of yeastsupplemented feed on Salmonella and Campylobacter populations in broilers. Poult Sci. 1998;77(3):405-410. doi:10.1093/ ps/77.3.405.

25. Marteau P, Rambaud JC. Potential of using lactic acid bacteria for therapy and immunomodulation in man. FEMS Microbiol Rev. 1993; 12(1-3):207-220.

26. Duke G. Avian digestion. Physiology of Domestic Animals. 1977;9:313-320.

27. Sissons JW. Potential of probiotic organisms to prevent diarrhoea and promote digestion in farm animals-a review. J Sci Food Agric. 1989;49(1):1-13. doi:10.1002/jsfa.2740490102.

28. Dierick NA. Biotechnology aids to improve feed and feed digestion: enzymes and fermentation. Arch Anim Nutr. 1989;39(3):241-261. doi:10.1080/17450398909429530.

29. Chiang SH, Hsieh WM. Effect of direct-fed microorganisms on broiler growth performance and litter ammonia level. Asian-Australas J Anim Sci. 1995;8(2):159-162. doi:10.5713/ ajas.1995.159.

30. Yeo J, Kim KI. Effect of feeding diets containing an antibiotic, a probiotic, or yucca extract on growth and intestinal urease activity in broiler chicks. Poult Sci. 1997;76(2):381-385. doi:10.1093/ $\mathrm{ps} / 76.2 .381$

31. Kumprecht I, Zobac P. The effect of probiotic preparations containing Saccharomyces cerevisae and Enterococcus faecium in diets with different levels of beta-vitamins on chicken broiler performance. Czech Journal of Animal Science-UZPI (Czech Republic). 1998;43:63-70.

32. Tannock GW. Probiotic properties of lactic-acid bacteria: plenty of scope for fundamental R \& D. Trends Biotechnol. 1997;15(7):270274.

33. McCartney AL, Wenzhi W, Tannock GW. Molecular analysis of the composition of the bifidobacterial and lactobacillus microflora of humans. Appl Environ Microbiol. 1996;62(12):4608-4613.

34. Freter R. Factors affecting the microecology of the gut. In: Probiotics: The scientific basis. Dordrecht: Springer; 1992:111 144.

35. Chateau N, Castellanos I, Deschamps AM. Distribution of pathogen inhibition in the Lactobacillus isolates of a commercial probiotic consortium. J Appl Bacteriol. 1993;74(1):36-40.

36. Fijan S. Microorganisms with claimed probiotic properties: an overview of recent literature. Int J Environ Res Public Health. 2014;11(5):4745-4767. doi:10.3390/ijerph110504745.

37. Garriga M, Pascual M, Monfort JM, Hugas M. Selection of lactobacilli for chicken probiotic adjuncts. J Appl Microbiol. 1998;84(1):125-132.

38. Blankenship LC, Bailey JS, Cox NA, Stern NJ, Brewer R, Williams O. Two-step mucosal competitive exclusion flora treatment to diminish salmonellae in commercial broiler chickens. Poult Sci. 1993;72(9):1667-1672. doi:10.3382/ps.0721667.

39. Tortuero F. Influence of the implantation of Lactobacillus acidophilus in chicks on the growth, feed conversion, malabsorption of fats syndrome and intestinal flora. Poult Sci. 1973;52(1):197-203. doi:10.3382/ps.0520197.

40. Szylit O, Champ M, Ait-Abdelkader N, Raibaud P. [Role of five Lactobacillus strains on carbohydrate degradation in monoxenic chickens]. Reprod Nutr Dev. 1980;20(5b):1701-1706.

41. Jin LZ, Ho YW, Abdullah N, Jalaudin S. Influence of dried Bacillus substillis and lactobacilli cultures on intestinal microflora and performance in broilers. Asian-Australas J Anim Sci. 1996;9(4):397404. doi:10.5713/ajas.1996.397.

42. Collington GK, Parker DS, Armstrong DG. The influence of 
inclusion of either an antibiotic or a probiotic in the diet on the development of digestive enzyme activity in the pig. Br J Nutr. 1990;64(1):59-70.

43. Goldin B, Gorbach SL. Alterations in fecal microflora enzymes related to diet, age, Lactobacillus supplements, and dimethylhydrazine. Cancer. 1977;40(5 Suppl):2421-2426.

44. Goldin BR, Gorbach SL. The effect of milk and lactobacillus feeding on human intestinal bacterial enzyme activity. Am J Clin Nutr. 1984;39(5):756-761. doi:10.1093/ajcn/39.5.756.

45. Cole CB, Anderson PH, Philips SM, Fuller R, Hewitt D. The effect of yoghurt on the growth, lactose-utilizing gut organisms and $\beta$-glucuronidase activity of caecal contents of a lactose-fed, lactase-deficient animal. Food Microbiol. 1984;1(3):217-222. doi:10.1016/0740-0020(84)90037-6.

46. Cole CB, Fuller R, Newport MJ. The effect of diluted yoghurt on the gut microbiology and growth of piglets. Food Microbiol. 1987;4(1):83-85. doi:10.1016/0740-0020(87)90021-9.

47. Nahashon SN, Nakaue HS, Mirosh LW. Production variables and nutrient retention in single comb White Leghorn laying pullets fed diets supplemented with direct-fed microbials. Poult Sci. 1994;73(11):1699-1711. doi:10.3382/ps.0731699.

48. Nahashon SN, Nakaue HS, Mirosh LW. Effect of direct fed microbials on nutrient retention and production parameters of single comb white leghorn pullets. Poult Sci. 1993;72(Suppl 2):87.

49. Nahashon SN, Nakaue HS, Mirosh LW. Effects of direct fed microbials on nutrient retention and parameters of laying pullets. Poult Sci. 1992;71(Suppl 1):111.

50. Nahashon SN, Nakaue HS, Mirosh LW. Performance of Single Comb White Leghorn fed a diet supplemented with a live microbial during the growth and egg laying phases. Anim Feed Sci Technol. 1996;57(1-2):25-38. doi:10.1016/0377-8401(95)00852-7.

51. Stuart RL, Surprise HC, Davis LW. Response of growing rats to diets supple mented with a liquid, non-viable, Lactobacillus fermentation product. J Anim Sci. 1978;47:322.

52. Schwab CG, Moore JJ, Hoyt PM, Prentice JL. Performance and fecal flora of calves fed a nonviable Lactobacillus bulgaricus fermentation product. J Dairy Sci. 1980;63(9):1412-1423. doi:10.3168/jds.S0022-0302(80)83098-0.

53. Perdigon G, Alvarez S, Rachid M, Aguero G, Gobbato N. Immune system stimulation by probiotics. J Dairy Sci. 1995;78(7):15971606. doi:10.3168/jds.S0022-0302(95)76784-4.

54. Perdigon G, Alvarez S, Nader-Macias ME, Roux ME, de Ruiz Holgado AP. The oral administration of lactic acid bacteria increase the mucosal intestinal immunity in response to enteropathogens. J Food Prot. 1990;53(5):404-410. doi:10.4315/0362$028 x-53.5 .404$.

55. Dunham HJ, Laster SM, Edens FW, Casas IA, Dobrogosz WJ. Immunomodulation of stressor-associated diseases in neonate chickens and turkeys by gastrointestinal colonization with Lactobacillus reuteri. J Immunol 1993;150:A197-A197.

56. Hosseini Z, Nassiri Moghaddam H, Kermanshahi H, Kalidari GA. Effect of probiotic (Bifidobacterum and Streptococcus) on performance and serum parameters of broiler chickens. Int J Agric Crop Sci. 2012;4:1-6.

57. Mahajan P, Sahoo J, Panda PC. Effect of probiotic (Lacto-Sacc) feeding, packaging methods and seasons on the microbial and organoleptic qualities of chicken meat balls during refrigerated storage. J Food Sci Technol (Mysore). 2000;37(1):67-71.

58. Jin LZ, Ho YW, Abdullah N, Jalaludin S. Growth performance, intestinal microbial populations, and serum cholesterol of broilers fed diets containing Lactobacillus cultures. Poult Sci. 1998;77(9):1259-1265. doi:10.1093/ps/77.9.1259.

59. Midilli M, Tuncer SD. The effects of enzyme and probiotic supplementation to diets on broiler performance. Turk J Vet Anim Sci. 2001;25(6):895-903.

60. Kabir SML, Rahman MM, Rahman MB, Rahman MM, Ahmed SU. The dynamics of probiotics on growth performance and immune response in broilers. Int J Poult Sci. 2004;3(5):361-364. doi:10.3923/ijps.2004.361.364.

61. Khbaksefidi A, Rahimi SH. Evaluation of the effect various levels of probiotic on blood factors, performance and carcass characteristics of broiler chicks under acute heat stress. Agric Sci Technol. 2004;18(2):149-158.

62. Karimi K, Rahimi SH. The effect of various levels of probiotic on performance of broilr chicks. Pajouhesh-va-Sazandegi. 2003;16(60):90-94. [Persian].

63. Kafilzadeh F, Safari Parvar MR. The effect of feeding different levels of immunobac probiotic on the performance of broilers. J Agric Sci Nat Resour. 2003;9(4):173-184.

64. Beheshti Moghadam MH, Rezaei M, Niknafs F, Sayyahzadeh H. Effect of combined probiotic and organic acid on some blood parameters and immune system of broiler chicks. Proceedings of the 2nd Mediterranean Summit of World Poultry Science Association; Antalya, Turkey; 2009:4-7.

65. Rowghani E, Arab M, Akbarian A. Effects of a probiotic and other feed additives on performance and immune response of broiler chicks. Int J Poult Sci. 2007;6(4):261-265. doi:10.3923/ ijps.2007.261.265.

66. Dalloul RA, Lillehoj HS, Tamim NM, Shellem TA, Doerr JA. Induction of local protective immunity to Eimeria acervulina by a Lactobacillus-based probiotic. Comp Immunol Microbiol Infect Dis. 2005;28(5-6):351-361. doi:10.1016/j.cimid.2005.09.001.

67. Haghighi HR, Gong J, Gyles CL, et al. Modulation of antibodymediated immune response by probiotics in chickens. Clin Diagn Lab Immunol. 2005;12(12):1387-1392. doi:10.1128/ cdli.12.12.1387-1392.2005.

68. Khaksefidi A, Ghoorchi T. Effect of probiotic on performance and immunocompetence in broiler chicks. J Poult Sci. 2006;43(3):296300. doi:10.2141/jpsa.43.296.

69. Gharib Naseri K, Rahimi S, Khaki P. Comparison of the effects of probiotic, organic acid and medicinal plant on Campylobacter jejuni challenged broiler chickens. J Agric Sci Technol. 2012;14:1485-1496.

70. Kabir SML. Effect of probiotics on broiler meat quality. Afr J Biotechnol. 2009;8(15):3623-3627.

71. Loddi MM, Gonzales E, Takita TS, Mendes AA, Roca Rde O. Effect of the use of probiotic and antibiotic on the performance, yield and carcass quality of broilers. Rev Bras Zootec. 2000;29(4):11241131. doi:10.1590/S1516-35982000000400025.

72. Zhang AW, Lee BD, Lee SK, et al. Effects of yeast (Saccharomyces cerevisiae) cell components on growth performance, meat quality, and ileal mucosa development of broiler chicks. Poult Sci. 2005;84(7):1015-1021. doi:10.1093/ps/84.7.1015. 